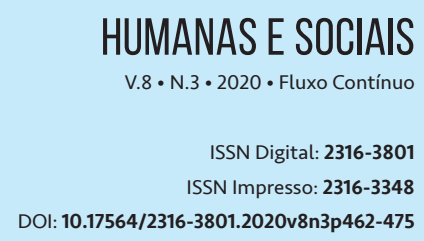

\section{RELAÇ̃̃ES DE GÊNERO E TRABALHO DOCENTE: EXPERIÊNCIAS DE PROFESSORAS NO ENSINO FUNDAMENTAL}

GENDER RELATIONS AND TEACHING WORK: EXPERIENCES OF TEACHERS IN FUNDAMENTAL TEACHING

RELACIONES DE GÉNERO Y TRABAJO DOCENTE: EXPERIENCIAS DE PROFESORAS EN LA ENSEÑNANA FUNDAMENTAL

\section{RESUMO}

Este trabalho analisa sob a perspectiva de gênero, 0 sentido, o significado do trabalho, a valorização da qualificação e de novas competências para as professoras do Ensino Fundamental da Escola Estadual Professor Valnir Chagas na cidade de Aracaju/Se, destacando avanços obtidos na construção da identidade, na ampliação dos direitos e da cidadania. A metodologia recaiu na abordagem qualitativa por esta permitir a coleta e análise de dados de maneira aprofundada, considerando-se os aspectos explícitos e implícitos do fenômeno estudado, além de proporcionar a explicitação das subjetividades. Foram consultadas diferentes fontes de informação: documentos, estatísticas oficiais, priorizando-se as fontes orais por meio de entrevistas semiestruturadas realizadas com sete professoras da referida escola. As docentes respondentes não mostram familiaridade com a abordagem de gênero; elas tendem a expressar representações naturalizadas sobre a construção das diferenças. A histórica divisão social e sexual do trabalho dificulta o processo de construção de identidades, e, por conseguinte a ampliação dos direitos e da cidadania. Mesmo diante das dificuldades enfrentadas, contraditoriamente elas consideram que os atributos de gênero não interferem na construção de seus projetos profissionais e vice-versa, definindo possibilidades de qualificação e mobilidade no mercado de trabalho.

\section{PALAVRAS-CHAVE}

Gênero. Trabalho Docente. Ensino Fundamental. Identidade. 


\section{ABSTRACT}

This study analyzes, from a gender perspective, the meaning, the meaning of the work, the valorization of the qualification and new competences for the teachers of Elementary School of the State School Teacher Valnir Chagas in the city of Aracaju / Se, highlighting the advances obtained in construction of identity, in the expansion of rights and citizenship. The methodology fell into the qualitative approach because it allows the collection and analysis of data in a thorough way considering the explicit and implicit aspects of the phenomenon studied, in addition to providing the explicitness of the subjectivities. Different sources of information were consulted: documents, official statistics, and oral sources were prioritized through semi-structured interviews with seven female teachers. Respondent teachers are not familiar with the gender approach; they tend to express naturalized representations about the construction of differences. The historical social and sexual division of labor hinders the process of building identities, and hence the expansion of rights and citizenship. Even faced with the difficulties they face, they contradictly consider that gender attributes do not interfere in the construction of their professional projects and vice versa, defining possibilities of qualification and mobility in the labor market.

\section{KEYWORDS}

Gender. Teaching work. Elementary School. Identity.

\section{RESUMEN}

Este trabajo analiza bajo la perspectiva de género, el sentido, el significado del trabajo, la valorización de la cualificación y de nuevas competencias para las profesoras de la Enseñanza Fundamental de la Escuela Estatal Profesor Valnir Chagas en la ciudad de Aracaju/Se, destacando avances obtenidos la construcción de la identidad, la ampliación de los derechos y la ciudadanía. La metodología recayó en el abordaje cualitativo por ésta permitir la recolección y análisis de datos de manera profundizada considerando los aspectos explícitos e implícitos del fenómeno estudiado, además de proporcionar la explicitación de las subjetividades. Se consultaron diferentes fuentes de información: documentos, estadísticas oficiales, priorizando las fuentes orales por medio de entrevistas semiestructuradas realizadas con siete profesoras de dicha escuela. Las docentes respondidas no muestran familiaridad con el enfoque de género; tienden a expresar representaciones naturalizadas sobre la construcción de las diferencias. La histórica división social y sexual del trabajo dificulta el proceso de construcción de identidades y, por consiguiente, la ampliación de los derechos y la ciudadanía. Incluso ante las dificultades enfrentadas, contradictoriamente ellas consideran que los atributos de género no 
interfieren en la construcción de sus proyectos profesionales y viceversa, definiendo posibilidades de cualificación y movilidad en el mercado de trabajo.

\section{PALABRAS CLAVE}

Género. Trabajo docente. Enseñanza fundamental. Identidad.

\section{INTRODUCÇÃO}

O presente texto expressa as sínteses da nossa dissertação de mestrado ${ }^{3}$ e tem como objetivo analisar sob a perspectiva de gênero, o sentido, o significado do trabalho, a valorização da qualificação e de novas competências para as professoras do Ensino Fundamental da referida escola, destacando avanços obtidos na construção da identidade, na ampliação dos direitos e da cidadania. Assim, contamos com a participação de sete mulheres docentes da referida escola e a coleta de dados foi feita por meio da entrevista semiestruturada e de questionário para informações complementares.

Historicamente, em diferentes sociedades, as mulheres e os homens se estabelecem e por meio da modificação da natureza, produzem sua existência, bem como produzem bens materiais, culturais e ideias. Não obstante, faz-se mister salientar que as ideias e os conhecimentos germinados em um dado momento histórico refletem a realidade contemporânea, visto que tais ideias produzidas socialmente estão no alicerce da sociedade e por conseguinte orientam as ações dos sujeitos, no entanto, eles tendem a modificá-las.

Nessa linha de reflexão, compreende-se que as representações são estruturadas pelo contexto histórico e pela sociedade e se constituem em exigências para a mulher e para o homem, cujas experiências são distintas, em cada tempo histórico, bem como não são constituídas de modo atemporal. No entanto, nem sempre a mulher foi percebida como sujeito da história. Corroborando com nossa afirmativa, Follador (2009, p. 3) destaca que "por muitos séculos as mulheres ficaram em segundo plano quando o assunto relacionava-se à história e feitos da humanidade. Trancafiadas em castelos, palácios ou simples moradias, as mulheres não tinham vez na história escrita pelos homens".

Nesse sentido, a história das mulheres é fundamental para se compreender a história geral, visto que ela é relacional e inclui tudo o que envolve o indivíduo, ou seja, o ser humano, suas perspectivas e concretizações, suas construções e derrotas e o seu grupo social. Tal abordagem demanda apresentar ideias, episódios e perspectivas para todos que anseiam refletir sobre a contemporaneidade e/ou procuram nela intervir, isto é, busca abordar a mulher por meio das tensões e das contradições estabelecidas em diferentes períodos e sociedades, por assoalhar as relações entre a mulher e o gru-

3 Dissertação desenvolvida no Programa de Pós-graduação em Educação da Universidade Federal de Sergipe intitulada “Relações de gênero, trabalho e formação docente: experiências de mulheres da Escola Estadual Professor Valnir Chagas”. 
po, tendo como meta mostrar que ela, como ser social, articula-se com o fato social, tendo em vista o molde patriarcal operante. Portanto, as modificações da cultura e as alterações nas ideias nascem dos problemas de uma época, de um indivíduo, independentemente de ser homem ou mulher.

Segundo Louro (2010), a construção do gênero é histórica e se faz incessantemente, na qual as relações entre homens e mulheres, os discursos e as representações dessas relações estão em constante mudança. Assim, as identidades de gênero estão continuamente se transformando. Scott (1990) utiliza-se de duas proposições para definir gênero: Para a autora, este é um elemento constitutivo das relações sociais baseadas nas diferenças percebidas entre os sexos e é uma forma de dar significado às relações de poder. Ela articula gênero com classe social e raça/etnia, revelando desigualdades e jogos de poder nestes três eixos.

Nesta multideterminação os sujeitos são constituídos, subvertendo a lógica cartesiana, linear e dicotômica, tornando gênero uma poderosa ferramenta de análise para compreender as complexas formas de interação humana. Especificamente no setor ocupacional, a despeito do grande aumento da participação feminina no mercado de trabalho, não se registrou diminuição significativa das desigualdades entre homens e mulheres

Ancoradas na tese da construção histórica e social dessas desigualdades e dos jogos de poder estabelecidos nas relações de gênero, buscamos traçar paralelos possíveis entre as categorias trabalho e gênero e a dialética da inclusão/exclusão. Assim, a posição da mulher na família e na sociedade, em geral, apresenta características patriarcais. Isto porque o patriarcado foi um elemento crucial em nossa organização social.

Algumas características, ao longo da história, separam o que é próprio de homem e de mulher; ou seja, o sexo determina não apenas quem faz o quê, mas também quem toma as decisões, visto que tanto homens quanto mulheres desempenham um papel produtivo e comunitário nas esferas familiar, cultural e social. Entretanto, o homem tradicionalmente assume o papel de representação pública, ao passo que a mulher desempenha um papel organizador fundamental no espaço privado da família, embora seja menos visível, o que favorece, desta forma, o sexo masculino em detrimento da subordinação feminina.

0 poder que intercede as relações entre os gêneros tem determinado para a mulher uma condição de subordinação. Isso posto, faz-se mister salientar que o acesso à educação e, posteriormente, ao mercado de trabalho tem se apresentado nada igualitário para mulheres e homens. Portanto, as mudanças obradas no mundo do trabalho e a própria evolução histórica da função exercida pelas mulheres, nos distintos espaços da sociedade contemporânea, possibilitam uma participação significativa das mulheres no espaço público. Porém, ainda é perceptível uma maior expressividade masculina.

É importante ressaltar a existência de lugares naturais e fixos para cada gênero, lugares esses percebidos pelos sujeitos como "naturais". No entanto, tal naturalização impede muitas vezes que visualizemos o quanto esses estão mergulhados em representações intermináveis que legitimam as estruturas sociais e, por conseguinte, deixam à margem grupos como mulheres, negros, pobres, homossexuais, pessoas com deficiência, entre outros, na medida em que são criadas representações ideais de seres humanos: homem, branco, heterossexual, casado, reprodutor e cristão, excluindo assim os demais grupos sociais. 
Nesse sentido, Louro (2010, p. 24) sinaliza que, segundo as críticas dos Estudos Feministas e dos Estudos Culturais, os sujeitos podem ser compreendidos como tendo identidades plurais, múltiplas; identidades que se transformam, que não são fixas ou permanentes, que podem, até mesmo, ser contraditórias, onde o sujeito passa a se perceber como se estivesse sendo "empurrado em diferentes direções", tendo em vista o sentido de pertencimento a diferentes grupos, a saber; étnicos, sexuais, de classes, de gênero, entre outros, que o constituem como sujeito.

Ao refletirmos acerca da divisão sexual do trabalho, notamos que no século XIX, temos como elemento do desenvolvimento do sistema capitalista/patriarcal a concretização das bases materiais e simbólicas da divisão sexual do trabalho. No século XX, mais precisamente a partir dos anos de 1970, revela-se o feminismo contemporâneo, que analisou e teorizou acerca dessa divisão, avançando na teoria crítica e pondo em questionamento o conceito de trabalho, que ao longo do tempo foi mencionado apenas ao trabalho produtivo, especialmente pela economia e pelas ciências sociais.

É importante observar que o trabalho reprodutivo ou trabalho doméstico, assim definido no contexto dessa sociedade, esteve fora do conteúdo que dava significado ao conceito de trabalho até muito recentemente e é a partir do movimento feminista que temos a reestruturação desse conceito com o intuito de alcançar as duas esferas do trabalho, visto que com o surgimento dos primeiros grupos feministas, bem como dos jornais feministas, o trabalho feminino diretamente no Brasil, na segunda metade da década de 1970, passou a ser tema de um intenso debate político, mesmo ainda tendo uma presença marginal na sociologia (ARAúJO, 2005).

O trabalho, a família e os mercados de trabalho vêm passando por profundas transformações que vêm se dando em virtude, principalmente, da inserção maciça das mulheres no mercado de trabalho remunerado e, este trabalho, por sua vez, quase sempre ocorre no espaço público, isto é, fora de seus lares. É fato inegável que o paradigma da divisão sexual do trabalho tem contribuído muito para o debate acerca do trabalho da mulher nos espaços reconhecidos como público e privado.

Faz-se mister destacar as contribuições teóricas acerca da divisão sexual do trabalho, que é denominada por Cruz (2005) como uma categoria de análise marxista que procura explicar as relações sociais de gênero e a divisão sexual presentes nas relações de trabalho e, por conseguinte, tende a entender como a divisão sexual do trabalho passou a ser pensada também no interior da família. Seguindo esse raciocínio, a autora apresenta como esse processo visualizou a construção social de espaço feminino, indissociável e que determinaria toda a posição desigual na sociedade, o que acarretaria também no modo como a mulher era excluída do mercado de trabalho. Não obstante, ainda destaca que essa discussão contribuiu para a incorporação da noção de divisão sexual do trabalho e ligou-a com a reprodução da força de trabalho.

As mulheres estão se inserindo gradualmente em lugares que até pouco tempo eram nichos masculinos, sendo o trabalho o principal espaço social da produção da identidade masculina (GROSSI, 2004). Os dados são crescentes, mesmo que esta conjuntura seja mais tímida do que em outras profissões e sejam colaboradas pelo aumento da demanda nos serviços ${ }^{4}$.

4 Observa-se que houve mudanças significativas no mercado de trabalho para a mulher, apesar de haver nichos inalterados, é oportuno registrar a significativa presença das mulheres nos espaços antes não ocupados por elas, a exemplo da construção 
As interpretações biológicas com o intuito de tentar legitimar a divisão sexual do trabalho socializaram o argumento de que a distinção entre trabalho masculino e feminino estaria relacionada à "natureza” dos homens e das mulheres, pois o homem, idealizado como provedor da família, estará designado para o trabalho da produção e a mulher, designada para o trabalho de reprodução, ocorrendo, por conseguinte, uma separação entre o público - masculino - e o privado - feminino.

A partir dessa reflexão é oportuno destacarmos que as delimitações do espaço de trabalho do homem e da mulher não são fixas, visto que sociedades e épocas diferenciadas podem ter concepções distintas acerca do que é mais “adequado" tanto para o homem, quanto para a mulher. Essa divisão também não se concretiza de forma homogênea, pois homens e mulheres podem desempenhar tarefas tanto no espaço público quanto no privado, ou seja, produtiva ou reprodutiva.

Percebe-se que a masculinização e a feminização de tarefas são construídas e associadas às representações sociais do masculino e do feminino. Sendo assim, as atividades masculinas notam predicados como força física, raciocínio lógico, dentre outras características tidas como "masculinas", assim como atividades femininas lembram atributos como paciência, destreza, atenção, entre outras características “femininas". Nessa perspectiva, nota-se que a inserção da categoria gênero na análise das relações sociais de trabalho, bem como outras variáveis como classe, raça, etnia, geração, por exemplo, possibilitam uma melhor apreensão dessa realidade, pois o mundo do trabalho está fortemente marcado por essas variáveis.

A esse respeito, Scott (1992) diz que falar de gênero é pontuar as questões políticas, no tocante à compreensão das relações de poder que se colocam na sociedade. Assim, o gênero remete não apenas a diferença entre os sexos na vida social, mas também as diferenças dentro da diferença. Ao incluir a reflexão sobre o corpo, Rago (2001) apresenta outra forma para compreender as questões de gênero e questiona como foi possível que, há algumas décadas, não incluíssemos o corpo em nossas reflexões sobre a sociedade, como se o ser humano fosse alma pura, mente abstrata, sem sexo, sem gênero, sem determinações culturais.

As relações entre homens e mulheres são, de modo geral, hierárquicas, desiguais e permeadas por mecanismos excludentes. A mulher constantemente é abordada na história como ser incompleto e que deve ao homem obediência e respeito.

\section{DISCUTINDO A FEMINIZAÇÃO DA DOCÊNCIA}

A partir da segunda metade do século XX, tem-se constatado no Brasil um crescente número de mulheres inseridas na carreira do magistério. Como em inúmeros outros países, o magistério é uma

civil. Em que pesem as críticas sobre as condições de trabalho, visto que a realidade da presença das mulheres na construção civil não ocorre de forma tranquila e sem conflitos, pois é difícil a busca de igualdade de gênero quando as lógicas da diferença calcadas na hierarquia estão impregnadas em alguns grupos da sociedade, frutos do processo de educação em que esses sujeitos foram socializados, as mulheres ao ocuparem esses espaços provocam uma desestabilização nas normas de gênero, mesmo que de formas distintas. 
atividade profissional considerada predominantemente feminina, visto que é perceptível que as mutheres representam a maioria na educação infantil. A feminização do magistério é um fato consumado e já percebido por todos. Mesmo diante dos questionamentos acerca das razões que levam as mulheres a escolher tal profissão, compreende-se que hoje as escolhas podem estar intrínsecas às mesmas razões que as mulheres do século XIX apresentavam mediante as escolhas pela profissão. Sendo assim, em uma escola, é perceptível facilmente a predominância feminina como professoras, psicopedagogas, secretárias, enfim, em todas as funções.

Paralelo a isso, vale salientar que as mulheres, durante longos e duros anos, foram excluídas da cidadania, devido aos interesses da família, bem como em virtude da sua diferença em relação aos "iguais" - os homens, as "necessidades" das mulheres foram definidas como limites para a garantia da cidadania e demoraram muito para serem reconhecidas como direitos individuais. Os seus "deveres”, por sua vez, foram colocados como motivo para elas serem excluídas da própria cidadania. A sua exclusão do espaço público é um forte elemento constitutivo das categorias de "cidadão" e de "político", assim, as dificuldades da posterior inclusão seriam indícios da construção das mulheres como não capazes de cidadania, conforme menciona Cruz (2009).

Igualmente, em sala de aula, tem-se notado que entre ser mulher-professora ou ser homem-professor há uma grande diferença, uma vez que se torna impossível ser professor ou professora e desvencilhar-se do gênero, pois, mesmo quando se veste a roupagem da educação, independentemente de ser homem ou mulher, não se deixa para trás sua história, sua formação nem sua sexualidade. Tudo isso está arraigado à construção histórica dos indivíduos e se faz necessário desvendar as artimanhas, os enlaces que construíram essa história.

A presença da mulher nos cursos docentes, bem como no mercado de trabalho operando como docente, é fruto de construção histórica, social, econômica e cultural. Sua inserção nesses espaços não foi dada de forma simples e não pensada, mas ocorreu após vários discursos que assinalaram fortemente tal necessidade e marcaram o ser, o pensar e o agir feminino, em suas diferentes identidades.

Temos a intenção de afirmar com isso que a inserção da mulher num espaço antes só destinado ao sexo masculino, foi construída, visto que o trabalho no espaço público, isto é, fora do espaço doméstico, não era comum, nem tampouco culturalmente aceito. Ora, tanto os discursos religiosos, quanto os positivistas apontavam a inferioridade da mulher, principalmente intelectual. Do mesmo modo, não havia aceitação do ingresso feminino no mercado de trabalho, nem na docência, visto que a natureza da mulher era considerada frágil e seu intelecto baixo, assim seria um verdadeiro absurdo a contratação de mulheres para a educação, principalmente das crianças.

A construção do ser mulher, bem como o tornar mulher, que fora estigmatizada socialmente, pode vir a incidir pelo viés ideológico, tendo como base a inferioridade feminina, o que para muitas mulheres são comportamentos de obediência, calma, serenidade, saber falar e calar no momento certo, habilidades que irão contribuir na escolha de profissões, haja vista que muitas são as atividades e comportamentos presenciados na escola que corroboram o processo de construção dessa naturalização.

Nesse sentido, faz-se necessário compreender que a desigualdade vivida pela mulher, em diferentes espaços e em diversos momentos, é socialmente construída muito cedo, ainda na educação 
infantil - ocorre ainda hoje a separação de meninas/meninos nas brincadeiras e atividades lúdicas - e tal separação é legitimada pelos docentes e aplaudida por muitos familiares.

As mulheres, mesmo diante de todas as limitações expostas, apropriaram-se desse discurso para assim ingressarem no mercado de trabalho por meio de uma profissão que lhes conferisse certa independência, passadio, reconhecimento, renda e elevação da autoestima.

Em meados do século XX, momento em que a inserção da mulher no mercado de trabalho ainda era muito tímida, as mulheres viam no ato de lecionar a saída para se dedicarem a outras atividades, sem abandonar o lar e os filhos, nem tampouco serem condenadas pelo abandono destes, já que era possível realizar esse trabalho somente recebendo salário, em meio período, sem interromper as atividades obrigatórias antes desempenhadas por elas, ou seja, ainda terem tempo para cuidar da família. Contudo, a realidade para as mulheres negras e de periferia não se apresentava da mesma forma, tendo em vista que sempre trabalharam e sustentaram suas famílias ${ }^{5}$.

Nesse sentido, Pessanha (2001) registra que a profissão de professora era desejável para mulheres de determinada classe social, no caso mulheres pobres e sem família, com uma perspectiva de, se não ascender socialmente, pelo menos não “decair" para um meio de vida “não decente”. Logo, percebe-se que quando as mulheres realizam a escolha do magistério como profissão, elas principiam, também, por meio dele, a buscar segurança, ascensão e autonomia. Nesse escopo, as identidades docentes são produzidas historicamente e sofrem interferências da própria experiência vivida.

\section{CONHECENDO O ESPAÇO DA PESQUISA}

A Escola Estadual Professor Valnir Chagas, localiza-se no município de Aracaju cujo corpo docente é constituído pelas professoras do ensino fundamental dos turnos matutino e vespertino. De acordo com o Instituto Brasileiro de Geografia e Estatística (IBGE), o Estado de Sergipe apresenta uma área de $21.918 .354 \mathrm{~km}^{2}$ e densidade demográfica de $94,35 \mathrm{hab} . / \mathrm{km}^{2}$. Tem uma população de 2.068 .017 pessoas, sendo 1.005.041 homens e 1.062.976 mulheres, distribuídas em 75 municípios (IBGE, 2010).

A Escola Professor Valnir Chagas campo empírico desta pesquisa, está sediada na Rua Itabaiana, no 313 Centro, Aracaju/SE, zona marcada pelo forte comércio, com poucas residências, próximo ao Quartel da Polícia Militar de Sergipe e à Delegacia de Atendimento a Grupos Vulneráveis (DAGV).

A unidade escolar está situada em uma área bastante estratégica para os alunos e familiares, mesmo estando próxima aos órgãos mencionados, é ponto desejado por bandidos e marginais que circulam em suas imediações, o que torna os discentes vulneráveis, visto encontrar-se próximo a uma praça ponto de encontro e de comércio de usuários de drogas ilícitas e assaltantes. Portanto, a presença desses órgãos não inibe a ação de tais sujeitos, bem como a ação de alunos pertencentes a

5 As mulheres avançaram e conquistaram direitos sociais, jurídicos e políticos, no entanto, esses direitos não se estenderam a mulher negra na mesma proporção da mulher branca, este desequilíbrio existente entre essas categorias de mulheres é um cenário histórico, que a mulher negra é inferiorizada em todos os aspectos humanos, apenas pela cor da pele, que é um traço da escravidão negra no Brasil. 
grupos organizados da própria escola e de outras escolas próximas, que agem dentro e fora da escola com atos de vandalismo e violência.

\section{CARACTERIZAÇ̃̃O DOS SUJEITOS}

Entre os séculos XIX e XX a docência foi progressivamente transferida do âmbito de atuação masculina para a feminina. Esse processo tem sido comumente justificado e naturalizado como características intrínsecas às mulheres. Entretanto, entendemos que o processo de feminização do magistério tem estirpes em mecanismos de poder geradores de formação das identidades profissionais do ser professora, com várias nuances e que vêm passando consecutivamente por modificações. No que se refere ao processo de feminização do magistério, os argumentos mais difundidos colocam como pontos fundamentais a falta de interesse dos homens em continuarem na profissão em virtude da "precarização da docência", em especial devido aos baixos salários; a "dificuldade" que a mulher apresenta em acessar outras profissões; compreensão no imaginário social de que essa seria uma profissão própria das mulheres, entre outros.

Isso posto, cabe salientar que durante a pesquisa na Escola Estadual Professor Valnir Chagas, constatou-se um número maior de professoras que professores, sendo dezesseis professoras e nove professores (CENSO ESCOLAR, 2012). No entanto, a pesquisa também nos apresentou um quantitativo interessante e igualitário de professores e professoras graduados e ministrando matemática, o que antes não era comum. Outro ponto que chamou atenção foi o fato de a escola não apresentar em seu quadro, professores de língua portuguesa e estrangeira.

A amostra foi composta de sete professoras do ensino fundamental dos turnos matutino e vespertino da Escola Estadual Professor Valnir Chagas, Aracaju/SE, independentemente da área e disciplina que ministram, do nível de instrução, idade, estado civil e filhos. São elas6: Afrodite, Artemis, Dakimi, Eva, Gaia, Hera e Oya. As respondentes, em seus relatos, salientam a necessidade de vermos a atividade docente como ato político, no qual a reflexividade do/a docente ganha espaço e significado, apontando a atuação docente para uma perspectiva emancipatória. Acreditamos que este trabalho foi interessante, pois possibilitou a todos(as) a consciência de que tanto os(as) docentes como os(as) discentes são sujeitos aprendizes e promotores da aprendizagem.

Neste trabalho, respondemos às questões preestabelecidas para a investigação inicial, ou seja, procuramos levantar no processo e responder a indagações relativas às relações de gênero, do trabalho e a formação docente das professoras, na medida em que as problemáticas das identidades de gênero nos espaços público e privado, na educação e no trabalho docente, no sentido e significado do trabalho docente, as qualificações e as mudanças nas relações do mercado de trabalho configura-se como um campo multidisciplinar de análise.

Percebe-se que as discussões acerca das relações de gênero no trabalho vêm apresentando avanço em alguns setores, enquanto em outros setores permanecem como tema ainda necessitando ser

6 Os nomes das participantes foram trocados para garantir a privacidade delas. 
aprofundado com mais sentido. Assim, justificamos o interesse desta pesquisa sobre as diversas dinâmicas que o trabalho docente tem transcorrido numa perspectiva macro/micro, internacional/nacional, objetiva/subjetiva e geral/particular.

A pesquisa proporciona visualizarmos a definição e os lugares atribuídos a homens e mulheres, a divisão social e sexual do trabalho e na família, bem como os aspectos que influenciam na construção de projetos e expectativas pessoais e profissionais que são vividas de maneira diferenciada entre homens e mulheres. No entanto, a pesquisa aponta a necessidade de continuar estes estudos com o intuito de ampliar a evolução teórica e empírica desse processo. Observa-se que nesse processo de escolhas e decisões, vários são os questionamentos, assim os procedimentos teórico-metodológico adotados para compreender as relações sociais de gênero construídas no trabalho docente foram significativos para nortear o desenvolvimento do trabalho e responder às questões e hipóteses levantadas.

No que se refere à caracterização dos perfis docente e discente da Rede Estadual de Ensino de Sergipe e da Escola Estadual Professor Valnir Chagas, esta foi realizada por meio da coleta de dados do Educacenso 2012, Projeto Pedagógico da Escola e da aplicação de questionários às docentes no decorrer de 2013. Os/as docentes do Valnir Chagas, em especial as professoras respondentes, são trabalhadoras do magistério estadual do ensino fundamental e apresentam perfil diversificado: níveis de atuação, nível de escolarização, remuneração, tempo de serviço, idade, estado civil e filhos.

Os discentes fazem parte de uma clientela com faixa etária de 10 a 17 anos de idade, oriundos de diversos bairros da capital e da grande Aracaju, a maioria deles é formada por filhos(as) dos comerciários da região. A escola apresenta Índice de Desenvolvimento da Educação Básica (IDEB) de 4.1, vinte e cinco turmas sendo do $6^{\circ}$ ao $9^{\circ}$ ano do ensino fundamental, tendo um total de 591 discentes matriculados e 25 docentes e cinco monitores de atividade complementar; segundo os dados obtidos, as mulheres representam maioria dos profissionais da instituição, principalmente em cargos de poder.

No tocante à idade, as respondentes apresentam de 38 a 62 anos e com filhos(as). A pesquisa aponta que das sete respondentes, quatro são divorciadas, o que revela uma tendência no aumento de docentes divorciadas. Assim, no que se refere ao encontro com a chefia familiar, as respondentes divorciadas se identificam como provedoras/chefes de família, o que ratifica um aumento considerável das famílias monoparentais e de lares chefiados por mulheres, bem como se configurou a tendência de diminuição do número de filhos, enquanto as respondentes casadas não se intitulam como provedoras e/ou chefes de família, mesmo apresentando renda superior à do cônjuge.

Quanto ao tempo de serviço na Rede Estadual de Ensino e na instituição investigada, motivação e escolha do trabalho docente, as respondentes apresentam entre seis a 25 anos na Rede Estadual de Ensino e entre um a oito anos na instituição, relatam que a motivação e as escolhas se deram devido ao fato de ser a opção mais “fácil” para ingresso na universidade e inserção no mercado de trabalho, como fator socioeconômico e vocação. Não obstante, quando questionadas acerca das possibilidades de mudar de profissão, relatam majoritariamente que não existe o interesse. Desta forma, a pesquisa conclui que o processo de inserção na carreira docente é diferenciado a partir do sexo do trabalhador e do fator socioeconômico.

Outros aspectos que merecem destaque são a jornada de trabalho, a divisão do trabalho doméstico, a administração da casa, a educação dos/as filhos/as, o trabalho produtivo e reprodutivo. Nesse sentido, quando questionadas, as respondentes majoritariamente relataram que são elas que cuidam 
dos afazeres domésticos e da educação dos/as filhos/as e chegam a contar com a presença de diaristas ou empregada doméstica, mesmo tendo a presença masculina (esposo) em casa. Quanto à jornada de trabalho no espaço público e privado, as respondentes salientam que uma não interfere na outra; no entanto, chegam a relatar que seria interessante ter mais tempo para os cuidados com elas mesmas.

Ao tentarmos compreender as concepções sobre o trabalho/profissão docente, a qualificação profissional e os atributos de gênero e barreiras aos projetos pessoais e profissionais, as respondentes relatam que sempre procuram melhorar, ampliando a qualificação profissional, percebem a importância do processo de qualificação para o desenvolvimento do trabalho docente e apontam positividade acerca do sentido e significado do trabalho docente, que se sentem satisfeitas com o bom desempenho e sucesso dos/as alunos/as nas disciplinas e participação nas atividades extras (projetos).

Contudo, apontam fatores que prejudicam o trabalho docente (baixos salários, sobrecarga de trabalho, estrutura física inadequada, ausência da família, desmotivação do/a aluno/a, entre outros) e salientam os danos que a profissão pode ocasionar (desgaste físico e mental, estresse, síndrome de burnout etc.). No que tange aos atributos de gênero (sexo, idade, estado civil, número e idade dos fi(hos), as respondentes demonstraram insegurança para responder, mas relatam as dificuldades para a realização de projetos pessoais e profissionais.

Ao analisar a estrutura da escola e condições de trabalho, bem como a diversidade e construção das diferenças na escola, as respondentes relatam as dificuldades em virtude da precariedade do espaço físico e as condições desfavoráveis de trabalho que prejudicam a todos (prejudicial em todo o processo ensino e aprendizagem) e apontam a necessidade de a educação pública ser levada a sério. Quanto à diversidade e construção das diferenças, os relatos apontam uma tendência à naturalização das diferenças no cotidiano de trabalho, bem como no seio familiar.

\section{BREVES APRECIACÕES CONCLUSIVAS}

A análise dos resultados deste trabalho e revisão de literatura nos permite concluir que ao arrancarem-se e serem arrancadas do lar, as mulheres, antes só percebidas como mulheres submissas e passivas, escravas obedientes dos maridos, tornam-se um exército que tende a lutar pelos seus próprios direitos, bem como pelos direitos e interesses da humanidade. Dessa forma, os momentos vivenciados com as respondentes nos trazem inquietudes e interrogações, visto que, concebidas a priori como seres incompletos, sujeitos a um constante aprendizado, a uma educação continuada, as respondentes sempre se questionavam: como devemos atuar na condição de professora nessa sociedade de sucessivas e apressadas mudanças? Como devemos digerir o conteúdo teórico formador, a gama de recursos tecnológicos e a nossa prática pedagógica?

Nesse sentido, acreditamos que o grande desafio é cantarmos uma única canção, isto é, enfrentarmos e "desfazermos" a cultura machista, inclusive dentro de nós, em nosso entorno, na Igreja e na Escola, assim construirmos uma nova cultura, em que homens e mulheres tenham os mesmos direitos e deveres. A luta que as mulheres enfrentaram para sair da invisibilidade, para serem reco- 
nhecidas como pessoas humanas com vontade e direito, não foi nada fácil, para entendermos basta pensarmos nas lutas pelo direito ao voto, ao estudo, à propriedade, ao ingresso no trabalho profissional, à isonomia salarial - até hoje, em muitas categorias profissionais, os seus salários continuam menores do que os dos homens.

Com isso, a pesquisa nos mostra que o/a professor/a que se torna reflexivo passa a ser um/a produtor/a de conhecimentos que permite uma melhoria em sua prática docente, fazendo assim uma análise mais profunda da organização das atividades, reformulando e realizando as alterações pertinentes para que o encaminhamento das suas aulas torne-se melhor estruturado, buscando um melhor desenvolvimento integral do seu aluno e aluna.

As respondentes entendem o sentido da formação continuada e percebem a importância em participar de programas voltados para a atualização profissional, porém algumas delas não buscam cursos, dentre outras capacitações e lamentam o fato de a rede de ensino não proporcionar. Isso foi possível observar dentro das questões em que questionamos e discutimos com as professoras em relação à qualificação profissional.

Não obstante, grande parte das respondentes, quando questionadas se a formação continuada ajuda na reflexão e numa possível mudança na prática pedagógica delas. As professoras acreditam sim numa possível mudança na prática pedagógica por meio de momentos de formação continuada. Também acreditam que com momentos diversos voltados para a prática docente, é possível adquirir novos conhecimentos e com isso buscar novas formas de desenvolver os conteúdos pertinentes.

Por fim, segundo as respondentes, a escola e a família são instituições fundamentais na formação humana, ética, técnica e profissional dos indivíduos. Estes pilares da sociedade fortalecem direitos e deveres, a liberdade, a transparência, princípios coletivos, enfim, propiciam a construção de uma civilização mais preparada para lidar com a vida.

O tempo passado com as respondentes nos faz concluir que na educação escolar as relações de gênero sempre constituíram guetos sexuais. Com o surgimento da escola vem um corpo professoral masculino e prossegue na história numa predominância alternada dos sexos, como uma instituição seletiva reprodutora de distinções, diferenças etc. Nestas condições, as relações de gênero da e na escola se reproduzem com muita fertilidade entrelaçadas pelo poder, pelo poder em todas as suas dimensões: o poder do Estado, da escola, do/a professor/a, da/o aluno/a, do homem, da mulher etc., como um reflexo do todo social no qual a escola está inserida.

A partir do conceito de gênero tornou-se possível analisar que essa separação expressa a construção social do masculino e do feminino bem como perceber que homens e mulheres ocupam todas as esferas, embora seja comum que eles desempenhem papéis sociais classificados como masculinos, já elas desempenhem papéis sociais considerados como femininos, que tais papéis não são naturais e podem ser modificados, também, tais mudanças inicialmente podem partir da escola. No entanto, essa instituição parece que mais ajuda na manutenção e legitimação da divisão sexual do trabalho do que na sua subversão, pois, ao mesmo tempo em que prepara profissionais para atividades "masculinas" e "femininas”, também reproduz ações e discursos que naturalizam essa divisão. 


\section{REFERÊNCIAS}

ARAÚJO, Angela M. C. Gênero nos estudos do trabalho (Para relembrar Elizabeth de Souza Lobo). In: MORAES, M. L. Q. de (org.). Gênero nas fronteiras do sul. Campinas: Unicamp/PAGU, 2005. Coleção Encontros.

CENSO ESCOLAR - Escola Estadual Professor Valnir Chagas. 2012.

CRUZ, Maria Helena Santana. Trabalho, gênero, cidadania: Tradição e Modernidade. São Cristóvão: Editora UFS; Aracaju: Fundação Oviêdo Teixeira, 2005.

CRUZ, Maria Helena Santana. Cidadania, crise do trabalho e gênero: desafios para estabilização dos direitos. In: NEVES, Paulo S. C. (org.). Educação, cidadania e questões contemporâneas. São Paulo: Cortez, 2009.

FOLLADOR, Kellen Jacobsen. A mulher na visão do patriarcado brasileiro: uma herança ocidental. In: Revista Fotos \& Versões, v. 1, n.2, p. 3-16, 2009.

IBGE - Instituto Brasileiro de Geografia e Estatística. Síntese dos Indicadores Sociais. Disponível em: www.ibge.gov.br. Acesso em: 3 out. 2013.

LOURO, Guacira Lopes. Gênero, sexualidade e educação: uma perspectiva pós-estruturalista. 11. ed. Petrópolis, RJ: Vozes, 2010.

PESSANHA, Eurize Caldas. Ascensão e queda do professor. São Paulo: Cortez, 2001.

RAGO, Margareth. Es que no es digna la satisfacción de lós instintos sexuales? amor, sexo e anarquia na revolução espanhola. In: SOARES, C. (org.). Corpo e história. Campinas: Autores Associados, 2001.

SANTOS, Elza Ferreira. Mulheres entre o lar e a escola: os porquês do magistério. São Paulo: Annablume, 2009.

SCOTT, Joan W. Gênero: uma categoria útil de análise histórica. In: Revista Educação e Realidade, Porto Alegre, v. 16, n. 2, jul./dez. 1990.

SCOTT, Joan W. História das mulheres. In: BURKE, P. (org.). A escrita da história: novas perspectivas. São Paulo: Unesp, 1992.

YANNOULAS, S. C. Dossiê: políticas públicas e relações de gênero no mercado de trabalho. Brasília: CFEMEA, FIG/CIDA. 2002. 
1 Doutora em Educação pelo Programa de Pós-Graduação da Universidade Federal de Sergipe; Mestrado em Educação pelo Programa de Pós-Graduação em Educação da Universidade Federal de Sergipe; Especialização em Didática e Metodologia do Ensino Superior pela Faculdade São Luís de França; Graduação em Serviço Social pela Universidade Tiradentes e Pedagogia pela Faculdade Regional de Filosofia, Ciências e Letras de Candeias; Membro do Grupo de Pesquisa do CNPq: "Educação, Formação, Processo de Trabalho e Relações de Gênero" e do Grupo "Gênero, Família e Violência" - UNIT; Professora Tutora do Centro Universitário UNINTA - Aracaju/SE.

E-mail: asantana1210@yahoo.com

2 Doutora e Mestra em Educação pela Universidade Federal da Bahia - UFBA; Pós-Doutora em Educação pela Universidade Federal de Sergipe - UFS; Lider do Grupo de Pesquisa: "Educação, Formação, Processo de Trabalho e Relações de Gênero" - UFS; Professora dos Programas de Pós-Graduação em Educação e Serviço Social - UFS.

E-mail: helenacruz@uol.com.br

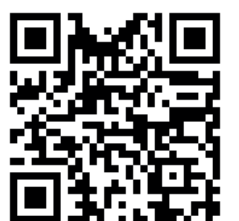

A autenticidade desse artigo pode ser conferida no site https://periodicos. set.edu.br

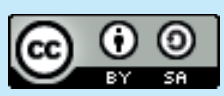

Este artigo é licenciado na modalidade acesso aberto sob a Atribuição-Compartilha Igual CC BY-SA

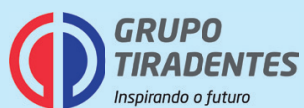

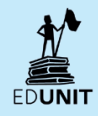

